\title{
APONTAMENTOS PRELIMINARES PARA O ESTUDO DA PRESENÇA dO ENSINO RELIGIOSO NA WEB
}

\author{
PRELIMINARY NOTES ON THE STUDY OF \\ THE PRESENCE OF RELIGIOUS EDUCATION ON THE WEB
}

\author{
SÉRGIO ROGÉRIO JUNQUEIRA ${ }^{(*)}$ \\ ELIANE APARECIDA LUNARDON ${ }^{(*)}$ \\ ROBSON MAURÍCIO GHEDINE ${ }^{(* * *)}$
}

\begin{abstract}
RESUMO
O Grupo de Pesquisa Educação e Religião em parceria com a Universidade La Salle de Bogotá (Colômbia) realiza uma pesquisa qualitativa documental no campo da diversidade cultural e educação escolar sobre o Brasil e Colômbia e suas implicações na atuação de professores. Neste processo iniciado em 2012 o grupo brasileiro está realizando suas pesquisas da atuação dos professores nas Redes Sociais objetivando compreender como este componente curricular está sendo difundido nestes instrumentos de repercussão na $W e b$, assim como estas informações estão interferindo na formação dos professores desta disciplina. É uma pesquisa qualitativa, documental organizado a partir do material identificado na Internet. Neste artigo a equipe apresenta a primeira etapa do trabalho desenvolvido que é a identificação e organização das fontes, assim como apresenta os critérios para posterior análise. Por ser um trabalho em uma área ainda pouco explorada optou-se por tornar público os primeiros resultados visando à discussão dos pesquisadores da área.
\end{abstract}

Palavras-Chave: Ensino Religioso. Redes Sociais. Internet.

\begin{abstract}
The Research Group Education and Religion in partnership with La Salle University in Bogota (Colombia) performs a qualitative study documentary in the field of cultural diversity and schooling on Brazil and Colombia and their implications in the performance of teachers. This process that started in 2012, the Brazilian group is conducting his research of the performance of teachers in Social Networks aiming to understand how this curriculum component is being disseminated in such instruments on the Web, as well as this information is interfering on the training of teachers of this discipline . It is a qualitative study Documentary arranged from the identified material on the Internet. In this article the research team presents the first stage of the work which is the identification and organization of sources and the criteria for further analysis. Being such a research in a little explored area the team decided to make the first public discussion of the results aimed at researchers.
\end{abstract}

Keywords: Religious Education. Social Networking. Internet.

INTRODUÇÃO

O Ensino Religioso, assim como outros componentes curriculares, possui amplos espaços para a pesquisa. Sobre este componente foram realizados

(*) Doutor em Ciências da Educação pela Universidade Salesiana de Roma, Itália. Pós-doutor em Ciências da Religião pela PUC-SP. Professor do Programa de Pós-Graduação Stricto sensu de Teologia da PUC-Paraná. Atua principalmente nos seguintes temas: educação, formação de professor, ensino religioso, ciências da religião e educação confessional. Email: srjunq@gmail.com.

${ }^{(* *)}$ Mestra em Teologia pela PUC-Paraná. Graduada em Letras e em Pedagogia. Especialista em Tecnologias na Educação e em Magistério Superior. E-mail: elianedias.lunardon@gmail.com.

${ }^{(* * *)}$ Mestrando em Teologia na PUC-Paraná. Bacharel em Filosofia e Teologia. Especialista em Educação à Distância. E-mail: robsonghedini@gmail.com. 
muitos estudos e outros ainda estão por ocorrer. Um trabalho a ser plenamente realizado é sobre a presença do Ensino Religioso na internet, especialmente no campo das Redes Sociais. Com essa perspectiva o Grupo de Pesquisa Educação e Religião iniciou um projeto de pesquisa em 2012 para compreender essa presença, estabelecendo como primeira etapa o levantamento dos sites, twitter, blogs, facebooks e outros. A partir deste mapeamento foram estabelecidos critérios para uma posterior análise e elaboração de um roteiro para os professores dessa área orientarem suas produções. Esse tema foi apresentado inicialmente em dois eventos: XI Educere - Congresso de Educação (Setembro 2013) e no VII Seminário Nacional e Internacional - Religião: O Espaço do Sagrado no século XXI, promovido pelo Núcleo Paranaense de Pesquisa em Religião (Outubro de 2013). Tomando como base o debate gerado com os participantes dos eventos, foram reconstruídos elementos que permitiram a construção deste texto que ora apresentamos ao leitor com o objetivo de abrir a discussão com os interessados no assunto.

O tema do Ensino Religioso na WEB é uma das estratégias de divulgação de idéias e concepções, assim, o presente estudo buscou compreender de que forma o Ensino Religioso se faz presente na internet. A proposta de uma nova concepção para o Ensino Religioso, como componente obrigatório dos horários normais das escolas públicas de Educação Básica, trouxe o desafio da formação dos profissionais docentes que assumiriam essa disciplina. Sendo assim, o estudo do referido tema faz-se urgente, uma vez que é necessário compreender a proposta do Ensino Religioso, bem como a formação de profissionais capacitados para a docência e para o mercado de trabalho na área afim.

Elegeu-se como objeto de investigação a questão da formação em Ensino Religioso e sua carência, buscando contemplar a esse respeito tanto os problemas quanto os desafios a serem estudados e superados. Partindo desse contexto, o objetivo principal desse artigo será analisar a proposta dos Blogs, Twitters, Facebooks e sites sobre o Ensino Religioso, enquanto componente curricular da Educação Básica brasileira. A escolha de publicar os primeiros resultados num periódico científico deve-se à expectativa de que a comunidade científica possa ler e questionar os conceitos e especialmente os critérios que serão apresentados a seguir, a fim de que esse trabalho possa produzir frutos proveitosos à pesquisa de maior envergadura que se encontra em desenvolvimento. $\mathrm{A}$ segunda etapa prevista é análise e classificação do material produzido para a internet e o projeto finalizará com a organização de um roteiro para professores sobre a criação e utilização da web para o apoio a formação e docência deste componente curricular. 


\section{CONCEPÇÃO DO ER}

O Ensino Religioso é um elemento do currículo, por estar alicerçado nos princípios da cidadania, do entendimento do outro enquanto outro, da formação integral do educando. Mesmo que muitas pessoas se neguem a pertencer a uma denominação religiosa, é um dado cultural que toda pessoa foi preparada para ser religiosa, para falar determinada língua, gostar disto ou daquilo, comer, existir de uma certa forma. Esses traços culturais são aprendidos, ao contrário dos traços genéticos, transmitidos biologicamente. Mais ainda: uma vez que no substrato de cada cultura sempre está presente o religioso, o ser religioso é, no mínimo, um dado antropológico, cultural.

Tal componente do currículo trata do conhecimento religioso. E esse conhecimento não é mera informação de conteúdos religiosos, um saber pelo saber. Verifica-se que de fato a identidade do Ensino Religioso no contexto das escolas está sendo solidificada a partir da leitura do pedagógico proposto pela relação do componente curricular no ambiente da sala de aula (Resolução $\mathrm{CNE} / \mathrm{CEB} \mathrm{n}^{\mathrm{o}}$ 07/10). Percebe-se que o Ensino Religioso necessita ser um conhecimento que, numa visão pedagógica progressista, oportuniza o saber de si: o educando conhecerá ao longo do período escolar os elementos básicos que compõem o fenômeno religioso, para que possa entender a sua busca do transcendente.

Ele é parte do convívio social dos educandos para que se respeite a tradição religiosa que já trazem de suas famílias e assim se salvaguarde a liberdade de expressão religiosa de cada um. Pois, é no respeito mútuo que se cultiva a reverência ao Transcendente que é UM, mas é MAIS pelas muitas formas de expressão, conforme as culturas. Assim o educando poderá se desenvolver no desarmamento pessoal e no empenho pelo entendimento mútuo, na paz e na fraternidade. Com esta proposta fica claro que o Ensino Religioso não busca fazer prosélitos (seguidores) de qualquer tradição.

Por meio dos conteúdos desse ensino visa-se proporcionar ao educando o contato com os conhecimentos básicos da composição do fenômeno religioso, os quais serão organizados em uma sequência cognitiva e em respeito às características próprias do desenvolvimento religioso do ser humano. Para tal, o Ensino Religioso está organizado nos seguintes eixos: teologias, textos orais e escritos sagrados, ritos e ethos, que serão transversalizados pelas culturas e tradições religiosas expressas na diversidade cultural-religiosa brasileira (FONAPER, 2001, 22 a 26).

A compreensão do Ensino Religioso, a partir de um perfil pedagógico, está 
dentro da problemática da compreensão da educação e do modelo de ciência que prevalece historicamente entre as teorias de aprendizagem e as práticas pedagógicas desenvolvidas. $\mathrm{Na}$ prática do professor encontra-se subjacente o modelo de educação e de escola, simultaneamente, influenciado pelo paradigma da ciência, traduzido tanto no discurso como na prática do cotidiano da sala de aula.

Muitas vezes esse referencial produz um confronto com o objetivo estabelecido pelo país para o Ensino Fundamental pretendido para a formação básica do cidadão, que deveria favorecer: o desenvolvimento da capacidade de aprender, tendo como meios básicos o domínio da leitura, da escritura e do cálculo; assim como a compreensão do ambiente natural e social, do sistema político, da tecnologia, das artes e dos valores em que se fundamenta a sociedade; o desenvolvimento da capacidade de aprendizagem, tendo em vista a aquisição de conhecimentos e habilidades e a formação de atitudes e valores; o fortalecimento dos vínculos de família, dos laços de solidariedade humana e de tolerância recíproca em que se assenta a vida social.

Nesse cenário é que os educadores podem ser desafiados a estabelecer o PERFIL PEDAGÓGICO deste componente curricular, em consonância com o Artigo dois da LDB (Lei nº 9.394, de 20 de dezembro de 1996): “A educação, dever da família e do Estado, inspirada nos princípios de liberdade e nos ideais de solidariedade humana, tem por finalidade o pleno desenvolvimento do educando, seu preparo para o exercício da cidadania e sua qualificação para o trabalho". Sobre a estruturação do atual modelo, Junqueira (2002, p. 19) explicita cinco características de um COMPONENTE CURRICULAR: 1) dominar linguagens; 2) compreender os fenômenos; 3) enfrentar situações; 4) construir argumentações; 5) elaborar propostas.

Nessa perspectiva, faz-se urgente promover um Ensino Religioso que acentue as informações no campo sociológico-fenomenológico, no qual o professor seja um professor e não um agente religioso e ao aluno seja permitido o acesso a questões do conhecimento. Essa concepção está explicitada por meio dos objetivos propostos em seu Parâmetro Curricular (FONAPER, 2006): valorizar o pluralismo e a diversidade cultural presente na sociedade brasileira, facilitando a compreensão das formas que exprimem o Transcendente na superação da finitude humana e que determinam, subjacente, o processo histórico da humanidade.

Por isso o Ensino Religioso necessita: a) propiciar o conhecimento dos elementos básicos que compõem o fenômeno religioso, a partir das experiências religiosas percebidas no contexto do educando; b) subsidiar o educando na formulação do questionamento existencial, em profundidade, para dar sua 
resposta devidamente informada; c) analisar o papel das tradições religiosas na estruturação e manutenção das diferentes culturas e manifestações socioculturais; d) facilitar a compreensão do significado das afirmações e verdades de fé das tradições religiosas; e) refletir o sentido da atitude moral, como conseqüência do fenômeno religioso enquanto expressão da consciência e da resposta pessoal e comunitária do ser humano; f) por fim, possibilitar esclarecimentos sobre o direito à diferença na construção de estruturas religiosas que têm na liberdade o seu valor inalienável.

Todo esse processo pressupõe o ser humano como um elemento de relações: que comunica e constrói - reconstrói e convive, sendo a escola convocada a contribuir para: aprender, fazer, viver e conviver (DELORS et al., 1998).

\section{NovOS ESPAÇOS PARA O ENSINO RELIGIOSO}

As discussões sobre o Ensino Religioso estão sendo divulgadas em diferentes espaços, inclusive na Rede mundial de computadores, pois não há dúvida de que esta facilitou as relações pessoais e o fluxo de informações entre redes de interesses comuns.

Aqui, faz-se necessária uma ressalva para esclarecer a diferença entre Internet e $W e b$; pois os termos são utilizados indistintamente como se fossem sinônimos, o que é não é correto. A Internet e a Web são coisas distintas, embora relacionadas. A Internet é uma infraestrutura em rede que conecta milhões de computadores globalmente, formando uma rede em que qualquer computador pode comunicar-se com qualquer outro computador, desde que ambos estejam conectados à Internet. A informação que viaja pela Internet o faz por meio de uma variedade de linguagens conhecidas por protocolos.

Para Kalinke (2003, p. 16) "a internet é, dentre as inovações tecnológicas, uma das ferramentas educacionais com maior possibilidade de agregar valores e ressaltar a importância dos professores.” É notório como a internet propicia esta agregação de valores. O mesmo autor ainda afirma que:

utilizando sites que permitam a interatividade, os alunos podem acessar atividades e recursos complementares que podem ser apresentados em uma grande variedade de mídias diferentes. Eles também podem interagir com o professor e outros alunos, além de compartilhar com eles os seus trabalhos. (2013.p. 18)

Tajra (2000, p.127) considera que a utilização da internet pode trazer vários ganhos pedagógicos, dentre os quais se destacam: a acessibilidade a fontes diversas de assuntos para pesquisa, as páginas educacionais especificas para a pesquisa escolar, as páginas para a busca de sofwares, a comunicação e 
interação com outras escolas, o estímulo para pesquisar a partir de temas previamente definidos ou a partir da curiosidade dos próprios alunos, a possibilidade de um desenvolvimento de uma nova forma de comunicação $e$ interação, favorecendo o estimulo à escrita e à leitura, a curiosidade e o raciocínio lógico, colaborando para o desenvolvimento da autonomia que orienta ao aprendizado individualizado e, por fim, a troca de experiências entre professores/professores, alunos/alunos e professores/alunos. Esses benefícios citados são motivadores quanto ao uso dessas tecnologias, devendo ser buscados pelos educadores como forma de construção de conhecimento, com o incentivo de alcançar a interatividade.

A Web é como um conjunto de páginas e sítios publicados na Internet e esta, por sua vez, é a infraestrutura de rede que liga os computadores em escala mundial. Nesse sentido, é possível identificar os computadores como instrumentos que servem para estabelecer uma interconexão tanto em redes locais quanto em redes dispersas em todo o mundo, rompendo, assim, com as limitações geográficas.

De acordo com Castells (1999, p. 422-425) devido às novidades trazidas pela era tecnológica, ocorreu uma "difusão de culturas pelo mundo, tornando-o cada vez mais virtualizado", isso porque o espaço-tempo foi encurtado, fazendo com que aumentasse a velocidade da informação passada. A sociedade, para ele, aderente a essa virtualização, é denominada "sociedade em rede".

Esta sociedade em rede, cada vez mais modernizada, opera de forma diferente. Muitas coisas que antigamente eram feitas de maneira manual, artesã, hoje são automatizadas, robotizadas e não passam mais pelo fazer humano, mas sim por sistemas computadorizados.

E em meio a essas mudanças, o processo educativo do ser humano foi impactado. A presença de computadores, tablets, vídeoaulas, blogs educacionais, quadros inteligentes e demais recursos tecnológicos dentro das salas de aula, traz à educação uma nova perspectiva. As novas Tecnologias da Informação e Comunicação (TICs) passaram a fazer parte da rotina escolar e, com isso, a vida acadêmica de professores e alunos foi modificada pela sua utilização.

Nesse contexto, é possível amigos se encontrarem no Facebook, no Twitter e em tantos outros "ambientes virtuais", e dessa forma, comunicarem-se e estabelecerem uma rede de amizade, trabalho ou estudo. Essas interações são denominadas de redes sociais na Internet, e hoje são impulsionadas por diversos sites e ferramentas exclusivos para este fim. Participar de uma rede social na Web é uma atividade que vem crescendo dia após dia, sendo importante ressaltar que se trata de uma ação intencional, pois é o indivíduo 
que opta em participar ou não de determinada comunidade ou grupos específicos.

É possível afirmar que as redes sociais são formadas por pessoas e por empresas conectadas entre si por diversos tipos de conexões (TOMAEL, ALCARA, Di CHIARA, 2005). Mas a explicação mais simples é a de que as redes sociais são um meio de se conectar a outras pessoas por intermédio de recursos (sites) na internet. As pesquisadoras Boyd e Ellison, em artigo para o Journal of Computer-Mediated Comunication ${ }^{1}$, definem os sites de redes sociais como:

Serviços baseados na web que permitem aos indivíduos: (1) construir um perfil público ou semi-público dentro de um sistema limitado, (2) articular uma lista de outros usuários com quem eles compartilham uma conexão, e (3) ver e percorrer a sua lista de conexões e aquelas feitas por outros dentro do sistema. A natureza e nomenclatura dessas conexões podem variar de site para site (BOYD e ELLISON, 2007).

Nesse sentido, as redes sociais podem ser entendidas como estruturas dinâmicas, desenvolvidas na Web, que podem aumentar e crescer de acordo com o número de usuários e as interações que estes vão realizando, uma vez que os sites de redes sociais geralmente funcionam tendo como base os perfis de usuário - uma coleção de fatos sobre o que um usuário gosta ou não gosta, seus interesses, hobbies, escolaridade, profissão ou qualquer outra coisa que ele queira compartilhar. Ou seja, a finalidade das redes sociais é reunir um grupo de pessoas que estejam interconectadas por um ou mais fatores. Segundo Recuero:

[...] a interação é aquela ação que tem um reflexo comunicativo entre o indivíduo e seus pares, como reflexo social. A interação, pois, tem sempre um caráter social perene e diretamente relacionado ao processo comunicativo (RECUERO, 2005, p.31).

O chat (bate papo virtual) pode ser considerado o marco inicial das Redes Sociais na Internet, uma vez que possibilitou a interação entre vários usuários. Dessa forma, é possível afirmar que:

Os internautas saíram de uma posição pacífica, de simples usuários, para os construtores de conteúdos, ao mesmo tempo em que diminuiu distâncias, aproximando pessoas de todo o mundo e possibilitando a troca de informações e confidências por pessoas até então desconhecidas (ZANINI et al., 2010).

Recuero (2009, p.95) afirma que as redes sociais são mantidas pelo interesse dos atores em fazer amigos e dividir suporte social, confiança e reciprocidade. E lembra que as redes sociais estão disponíveis na Web, podendo representar

\footnotetext{
Disponível em: < http://jcmc.indiana.edu/vol13/issue1/boyd.ellison.html\#introduction > - (tradução
} livre). 
mais um excelente instrumento pedagógico, tanto para o processo de ensino e aprendizagem do aluno quanto para a formação continuada do professor. Nessa perspectiva é possível levantar o seguinte questionamento: "Por que então não utilizar os recursos disponíveis nas redes sociais para a formação do professor”?

Para justificar e reforçar a possibilidade do uso das redes sociais na formação continuada do professor, pode-se recorrer às palavras do professor João Mattar ${ }^{2}$, que em entrevista ao Portal de Educação e Tecnologia, afirma que: as redes sociais são mais usadas que os e-mails; são mais atrativas; permitem uma maior interação entre os usuários; e auxiliam a formar profissionais para trabalhar em grupos e em redes. Além de representarem uma nova possibilidade de serem utilizadas como instrumentos de educação a distância, uma vez que, por estarem disponíveis gratuitamente na $W e b$ e serem de uso comum, podem se configurar como ambientes virtuais de aprendizagem e contribuir com a formação do professor de Ensino Religioso.

Contudo é importante observar que na Internet estão disponíveis vários modelos de redes sociais, razão por que os professores devem estar aptos a pesquisar e selecionar aquelas que mais se adaptem aos seus objetivos e propostas pedagógicas. Faz-se, portanto, necessário conhecer algumas das principais redes sociais, bem como entender suas especificidades técnicas e possibilidades pedagógicas, com o propósito de utilizá-las como mais um recurso na educação presencial e também como um ambiente virtual de aprendizagem (AVA), a ser estudado e utilizado para o desenvolvimento de cursos que possibilitem tanto a qualificação quanto a formação continuada do professor.

\subsection{O FАCEBOOK}

O Facebook é um site e serviço de rede social que foi lançado em 2004; segundo dados da com Score, divulgados em janeiro, durante o mês de dezembro de 2011, o Facebook se tornou a rede social mais utilizada no Brasil, e, no mundo, atingiu a marca de mais de 845 milhões de usuários ativos.

O Facebook, por se configurar como uma rede que permite a interação entre os usuários e também a disponibilização de arquivos ou mídias específicas, pode ser um grande aliado ao trabalho pedagógico, principalmente para a educação a distância. Ao analisar esta rede social, é possível constatar a existência de uma

$2 \quad$ Disponível em: <http://www.educacaoetecnologia.org.br/?p=5487>. 
série de recursos ou tipos de ações, como: imagens; textos; vídeos; links; produção de enquetes; envio de mensagens; promoção de festas; criação de grupos diversos; tudo isso em uma única interface, concentrado em uma única página web.

Algumas características desta rede que podem ser aproveitadas pedagogicamente são: a interação entre as pessoas, que podem questionar ou comentar as postagens; a possibilidade de fazer intervenções na sequência e/ou reencaminhamento do mesmo texto para sua rede; e o compartilhamento com outras pessoas do seu próprio grupo, pois a interface possui atualização dinâmica e rápida. As imagens, vídeos e links recebem o mesmo tratamento dos textos escritos, ou seja, é possível curti-las, comentá-las e reencaminhá-las a outros usuários.

O Facebook ajuda também a promover debates e discussões muito interessantes, além de possibilitar que os estudantes postem imagens vídeos e indiquem os links das suas fontes de pesquisas.

\subsection{OTWITTER}

Twitter refere-se ao som que os pássaros fazem: 'piar', 'gorjear' ou 'trinar' em português; e refere-se também aos substantivos: 'pio', 'gorjeio', 'trinado', e em inglês é 'chirp'. Por isso o mascote do Twitter é um pássaro, e, também, é esta a razão da expressão em português 'eu tuito'.

O Twitter surgiu em 2006, como software desenvolvido para comunicação interna da ODEO INC: serviço que utilizava $S M S^{3}$ para pequenos grupos, avisando-os sempre sobre "o que você está fazendo". Atualmente, é uma rede social e servidor para microblogging, que permite aos usuários enviar e receber atualizações pessoais de outros contatos, em textos de até 140 caracteres, conhecidos como 'tweets'. No twitter é possível demonstrar uma ideia, resumir informações, transmitir conceitos e até escrever microcontos. Além disso, é possível também criar uma lista da sua sala ou uma hashtag (\#) de um assunto (palavras-chave que designam o assunto sobre o qual está se discutindo), bem como publicar links de vídeos, matérias, imagens.

Mas é necessário seguir as pessoas para receber o que elas escrevem, pois as atualizações são exibidas no perfil de um usuário em tempo real e também enviadas a outros usuários seguidores que tenham assinado para recebê-las. As atualizações de um perfil ocorrem por meio do site do Twitter, por RSS, por $S M S$ ou programa especializado para gerenciamento.

3 SMS é a sigla de Short Message Service, que significa Serviço de Mensagens Curtas, e é um termo de origem inglesa (trocadas entre telefones celulares e smartphones). No Brasil, o serviço é mais conhecido como "torpedo". Disponível em: http://www.significados.com.br/sms/. 
Em relação ao uso pedagógico, Steve Wheeler, especialista em e-learning da Faculdade de Educação da Universidade de Plymouth (Reino Unido), diz que o Twitter pode ser utilizado como quadro de avisos para socializar notícias e informações aos estudantes; para pedir resumos de textos; para compartilhar sites; para manter conversas nas quais participem todos os estudantes que assinam o Twitter; para produzir microtextos; e para realizar Intercâmbio cultural (aprender sobre outras culturas).

Enfim, o Twitter permite um excelente intercâmbio de informações com diversas outras redes sociais, entre elas o Facebook, em que é possível com que tudo que o usuário poste no Twitter seja postado em sua conta do Facebook e vice-versa. Outra vantagem do Twitter é que ele permite que o internauta possa definir que suas atualizações sejam particulares, podendo ser vistas apenas pelas pessoas que ele aprovar.

\section{$2.3 O B L O G$}

O Blog não é considerado uma rede social, mas é uma excelente ferramenta de comunicação e compartilhamento e registro de atividades e reflexões de grupos de pesquisa e de estudantes, podendo ser escrito individual ou coletivamente. Ele é um recurso da Web 2.o, muito simples e funciona como um portfólio digital (ou e-portifólio).

Em relação aos blogues, pode-se considerar duas categorias de uso: como recurso pedagógico e como estratégia educativa. Enquanto recurso pedagógico podem ser utilizados como um espaço de acesso a informação especializada e/ou como um espaço de disponibilização de informação por parte do professor. Enquanto estratégia educativa, os blogues podem servir como um portfólio digital, um diário de bordo, um espaço de intercâmbio e colaboração, um espaço de debate e/ou, ainda, como um espaço de integração.

Já, Orihuela \& Santos (2004) apontam três vantagens na utilização de blogues: a facilidade da criação e o manuseamento das ferramentas de publicação, o fato de a ferramenta disponibilizar interfaces que permitem ao usuário centrar-se no conteúdo e a existência de funcionalidades como comentários, arquivo, entre outros.

Ressalta-se que o Blog é considerado um poderoso instrumento de acompanhamento de pesquisas e, assim, pode ser utilizado como instrumento pedagógico na formação continuada do professor. Também é uma excelente forma de comunicação entre membros de uma família, amigos, grupos de trabalho, ou até mesmo empresas. Ele permite que grupos se comuniquem de forma mais simples e organizada do que através do e-mail ou 
grupos de discussão, por exemplo. Para criar e atualizar o Blog existem diferentes plataformas disponíveis na $W e b$ :

\subsubsection{Blogger 4}

O Blogger é uma ferramenta disponível na Internet, com a função de auxiliar o internauta a criar, publicar e atualizar seu blog a todo instante, de qualquer lugar do planeta, sem complicação ou programação. Por meio desse site é possível criar um blog privativo para uma equipe de trabalho ou discussão de projetos; ou criar um blog familiar para que parentes troquem entre si notícias e fotos.

\subsubsection{Wordpress 5}

O WordPress é um aplicativo de sistema de gerenciamento de conteúdo para web, voltado principalmente para a criação de blogs, gratuitamente, sendo adotado por aqueles que queiram um blog mais profissional e com maiores recursos diferenciais. A flexibilidade do Worldpress permite que o usuário administre seu conteúdo mesmo sem nenhum conhecimento de HTML ${ }^{6}$ ou PHP7. O WordPress é utilizado também como plataforma de desenvolvimento de sites de comércio eletrônico, revistas, jornais, portfólio, podcast, video blog, clone do Twitter, gerenciamento de projeto, diretório de eventos e outros conteúdos, devido a sua capacidade de extensão através de plugins, temas e programação PHP.

\subsubsection{Tumblr ${ }^{8}$}

O Tumblr, fundado em 2007 por David Karp, com o líder de desenvolvimento Marco Arment, é uma plataforma gratuita de microblogging com diversas funcionalidades típicas das redes sociais, principalmente a interação com outros usuários e sites - Wordpress, Blogger, Livejournal, Facebook e Twitter. Ressalte-se que o foco dessa rede social é o conteúdo. Assim, os usuários

4 Como criar um blog no Blogger. Disponível em: <http://www.gerenciandoblog.com.br/2013/o1/comocriar-um-blog-no- blogger.html.>

5 TECHTUDO. Como criar um domínio próprio no WordPress.

Disponível em:

<http://www.techtudo.com.br/dicas-etutoriais/noticia/2013/o7/como-criar-um-dominio-proprio-nowordpress.html.>

${ }^{6}$ HTML - 'HyperText Markup Language' - expressão inglesa que significa "Linguagem de Marcação de Hipertexto". Consiste em uma linguagem de marcação utilizada para produção de páginas na web.

Disponível em: <http://www.significados.com.br/html/.>

7 PHP - 'Hypertext Preprocessor': é uma linguagem de programação usada para gerar conteúdo para a WEB.

Disponível em: <http://www.infoescola.com/informatica/php/. >

8 CANALTECH. Como usar o Tumblr.

Disponível em: < http://canaltech.com.br/tutorial/tumblr/Como-usar-o-Tumblr/>. 
podem publicar textos, imagens, vídeo, links, citações, áudio e 'diálogos'. Os usuários são capazes de 'seguir' outros usuários e ver seus posts em seu painel, o 'dashboard'. Também é possível 'favoritar' o conteúdo desejado ou 'reblogar' algo postado por outro usuário, como ocorre no Twitter (retuitar). O Tumblr possui ferramentas de personalização que permite aos usuários usarem tags ${ }^{9}$ especiais para criarem seus themes ${ }^{10}$.

\subsubsection{My space $^{11}$}

O My Space é um aplicativo da rede social que oferece ao usuário atualizações dos seus contatos, possibilidade de publicação, gerenciamento de mensagens diretas, visualização e interação com suas notificações, além de bate papo com outros adeptos da rede; inclui um sistema interno de e-mail, fóruns e grupos. A interface da aplicação $M y$ Space é organizada e traz todos seus recursos já na tela inicial, e o fluxo de postagens pode ser visualizado por lista ou grade. Com o My Space o usuário pode manter-se atualizado das últimas postagens de seus amigos e também pode publicar novidades, inclusive com indicação de humor, sendo possível, também, atualizar os seus álbuns pelo dispositivo. O My Space foi criado em 2003 e já foi o mais popular do mundo, mas perdeu nos últimos anos para outras redes sociais.

\subsubsection{Zip.net ${ }^{12}$}

O Zip.net é um portal que pertence ao UOL, possui serviços como $e$-mail, bate-papo online, publicação instantânea de textos e imagens na Web (para assinantes e visitantes cadastrados no $U O L)$ e encurtador de $U R L s^{13}$. Foi lançado em agosto de 1998, e logo alcançou grande sucesso. Depois foi adquirido pela Portugal Telecom e se uniu aos serviços do UOL, excluindo todos os outros, inclusive o portal Zip, que retornou em 2010. Atualmente, o serviço tem $6 G B$ de capacidade. Os serviços mais populares do site são o Zipmail (email gratuito) e o ZipLink, que funciona como um atalho para endereços longos, pois reduz o tamanho dos links para que você possa compartilhá-los em

\footnotetext{
9 'Tag' em inglês quer dizer etiqueta. As tags na Internet são palavras que servem justamente como uma etiqueta e ajudam na hora de organizar informações, agrupando aquelas que receberam a mesma marcação, facilitando encontrar outras relacionadas. Disponível em: http://www.tecmundo.com.br/navegador/2051-o-que-e-tag-.htm.

10 Themes: vem do inglês e significa 'tema', assunto', 'enredo'.

Disponível em: http://oque.dictionarist.com/theme.

${ }_{11}$ Wordpress,org Brasil. Disponível em: <http://br.wordpress.org/>

12 Portal: UOL Blog. Disponível em <http://blog.uol.com.br/stc/passeio_virtual_1_1.html.>

13 URL - 'Uniform Resource Locator' - é um endereço virtual com um caminho que indica onde está o que o usuário procura. Disponível em: < http://www.significados.com.br/url/>.
} 
microblogs, redes sociais, e-mails e no celular. Ressalte-se que depois de encurtado, o endereço começará com 'http://zip.net' e terminará com um código alfanumérico, como por exemplo: 'http://zip.net/abc123'. E ao clicar nesse link, o internauta será automaticamente redirecionado para o endereço completo do site.

\section{OSITE}

Site, sítio, website ou sítio eletrônico é um conjunto de páginas web, isto é, de hipertextos acessíveis geralmente pelo protocolo HTTP na Internet, que são utilizadas para fazer referência a uma página ou a um agrupamento de páginas relacionadas entre si, acessíveis na rede mundial de computadores através de um determinado endereço. O conjunto de todos os sites públicos existentes compõe a World Wide Web. As páginas são organizadas dentro do site seguindo uma hierarquia observável no $U R L$, embora as hiperligações entre elas controlem o modo como o leitor se apercebe da estrutura global. Existem vários tipos de sites especializados em determinado serviço ou uso particular, como: os websites institucionais, midiáticos, informativos, pessoais, portais, comunitários etc. Cada um possui um objetivo, de acordo com o seu público alvo, pois é o propósito do site que direciona o trabalho do Webdesigner, que é o profissional que cria o website. Nos sites podem ser colocados textos, imagens, vídeos ou animações digitais e, assim, eles podem apresentar tanto uma forma estática quanto uma forma dinâmica e interativa. Estas páginas são carregadas por meio do protocolo de rede HTTP (Hypertext Transfer Protocol) e são visualizadas através de um navegador (browser).

\section{O Ensino Religioso na $W E B$}

$\mathrm{Na}$ pesquisa realizada entre os meses de março a junho de 2013 foram constatados 19 facebooks, 37 blogs, 02 twitters e 07 sites sobre o Ensino Religioso. Historicamente o mais antigo é o site do FONAPER que teve a sua primeira organização em 1998 e foi reestruturado em 2003. Posteriormente o site do GPER (Grupo de Pesquisa Educação e Religião) que é datado de 2005. Entre os blogs com registro de periodicidade podemos considerar o Blog Educação da Religiosidade - Prof. Felipe Souza, criado em 2007, como o mais antigo da rede. Entre os Twitters o primeiro é o Twitter Ensino Religioso Macaé, que data de 2010; e entre os facebooks está o Facebook Paulinas Diálogo, de 2011.

A primeira etapa desta pesquisa visou explicitar elementos do perfil dos 
autores do material produzido para as Redes Sociais. Percebeu-se que dos 65 identificados 37 foram desenvolvidos por indivíduos e 28 por instituições.

\begin{tabular}{|l|l|}
\hline Individual & 37 \\
\hline Institucional & 28 \\
\hline
\end{tabular}

Entre o material pesquisado com significatividade encontram-se os Blogs (27), seguidos pelos Facebooks (10). Não foi localizado nenhum twitter e nem sites. Isso pode ser explicado por terem os dois primeiros uma estrutura que favorece a sistematização e difusão das informações.

\begin{tabular}{lll}
\hline & Individual & Total \\
\hline Blog & 27 & 27 \\
Twitter & 00 & 00 \\
Facebook & 10 & 10 \\
Site & 00 & 00 \\
Total & 37 & 37 \\
\hline
\end{tabular}

O material produzido institucionalmente (28) foi organizado a partir da função de suas organizações: 7 foram propostos por Associações de Professores ou Grupos Inter-religiosos; 3 foram gerenciados por Secretarias de Educação (Sistema de Ensino); 8, por Instituições de Ensino Superior; 6, por Escolas da Educação Básica; e finalmente 4 são periódicos. Apresenta-se a seguir a tabela que permite a compreensão desta identificação.

\begin{tabular}{lllllll}
\hline $\begin{array}{l}\text { Institucion } \\
\text { al }\end{array}$ & $\begin{array}{l}\text { Associaçã } \\
\text { o }\end{array}$ & Sistema & IES & Periódico & Colégio & Total \\
\hline Blog & 02 & 01 & 03 & 00 & 04 & 10 \\
Twitter & 00 & 01 & 01 & 00 & 00 & 02 \\
Facebook & 02 & 00 & 03 & 02 & 02 & 09 \\
Site & 03 & 01 & 01 & 02 & 00 & 07 \\
Total & 07 & 03 & 08 & 04 & 06 & 28 \\
\hline
\end{tabular}

A partir desses dados percebe-se que os professores difundiram sua discussão sobre o Ensino Religioso no espaço dos Blogs pela praticidade, gratuidade das ferramentas e disponibilidade de atualização. Será necessário aguardar para confirmar ou não a migração desta presença significativa para o Facebook. Porém, institucionalmente constata-se o seguinte movimento: os colégios, associações e cursos comunicam-se por meio de blogs, periódicos, grupos de pesquisa, organização de sites e utilização de redes sociais para 
ampliar a interação com os leitores. Verificou-se que os números individuais são superior aos institucionais.

Visando utilizar as Redes Sociais para uma proposta explícita de formação continuada para professores de Ensino religioso foi elaborado um projeto utilizando o Facebook com esta perspectiva.

\section{CONSIDERAÇÕES}

Nesta primeira etapa da pesquisa foram localizados, selecionados, classificados os materiais para que na segunda etapa essas informações possam ser analisadas, visando a compreensão sobre o impacto da WEB no Ensino Religioso, especialmente nas Redes Sociais. Para tal estabeleceram-se alguns critérios para a sua leitura e análise dos dados.

\begin{tabular}{|l|l|}
\hline Forma & $\begin{array}{l}\text { Identificação do documento - se sua proposta é de Facebook, } \\
\text { twitter, site, blog, pois a partir de sua plataforma apresenta uma } \\
\text { organização própria. }\end{array}$ \\
\hline $\begin{array}{l}\text { Periodicidade e } \\
\text { contexto }\end{array}$ & $\begin{array}{l}\text { Identificação da origem e atualização do documento, sua origem } \\
\text { territorial. }\end{array}$ \\
\hline Autor & $\begin{array}{l}\text { Identificação do autor/currículo/ biografia; com isso pode-se } \\
\text { compreender se o mesmo tem autoridade para expor o assunto, } \\
\text { ou apenas quer expressar seus pensamentos a respeito. }\end{array}$ \\
\hline Destinatários & $\begin{array}{l}\text { Os destinatários do documento influenciam diretamente no } \\
\text { conteúdo a ser publicado. }\end{array}$ \\
\hline Conteúdo & $\begin{array}{l}\text { Apresentação de assuntos relevantes e atuais, denotando } \\
\text { preocupação em mostrar o assunto da maneira mais correta; cita } \\
\text { fontes, referências de suas citações, está preocupado em } \\
\text { demonstrar seriedade acadêmica e autenticidade de } \\
\text { informações. }\end{array}$ \\
\hline Impacto & $\begin{array}{l}\text { O número de visitantes mostra o quanto o documento tem sido } \\
\text { procurado como fonte e referência do assunto. }\end{array}$ \\
\hline Linguagem & $\begin{array}{l}\text { A objetividade e clareza de como as informações foram tratadas } \\
\text { em cada proposta (Twitter, Blog, Sites, Facebook). }\end{array}$ \\
\hline Imagem & $\begin{array}{l}\text { A coerência da utilização ou não de imagens como ilustração, } \\
\text { explicativa, qualificadora do texto. }\end{array}$ \\
\hline Teoria Pedagógica & $\begin{array}{l}\text { As informações estão adequadas a uma concepção teórica de } \\
\text { educação ou de ensino religioso reconhecida no páis. }\end{array}$ \\
\hline
\end{tabular}

Esses aspectos que unem o homem contemporâneo, sua prática religiosa e sua inserção nas redes sociais foram bem notados pelos critérios de análise apresentados. Tais critérios foram estabelecidos objetivando observar o objeto digital na perspectiva de que:

1- Quando está atualizado é contextualizado, traz assuntos relevantes e atuais, denotando preocupação em mostrar o assunto da maneira mais correta. 
2- Quando se tem acesso ao autor/currículo/ biografia pode-se compreender se o mesmo tem autoridade para expor o assunto, ou apenas quer expressar seus pensamentos a respeito.

3- Se ao citar as fontes e referências de suas citações está preocupado em demonstrar seriedade acadêmica e autenticidade de informações.

4- Se o número de visitantes mostra o quanto o blog tem sido procurado como fonte e referência do assunto.

5- Se a forma de interação nos objetos digitais, tais como respostas, comentários, compartilhar, curtir, twittar e suas respectivas construções coletivas ou contribuições individuais mostra um importante fator de impacto deste objeto e sua inserção na Sociedade.

No atual cenário mundial verifica-se uma constante interação entre o homem e a tecnologia. Com o passar do tempo cada vez mais homem e máquina interagem e se relacionam de maneira constante, a ponto dessa interação poder expressar-se atualmente pelo virtual das mais diversas formas.

Olhar para o homem é notar como ele se relaciona com a religião. Sendo um ser religioso, busca das mais diversas práticas para se relacionar com o Transcendente, cada uma de seu modo, e cada modo de acordo com seu tempo.

O Brasil é um país multicultural, e pela miscigenação racial incluiu em suas práticas religiosas as mais variadas formas de se relacionar com o Sagrado. Nesse interim, a religião estabelece sua relação com as redes sociais e a tecnologia e crescentemente apresenta-se como uma expressão contemporânea do homem de hoje.

\section{REFERÊNCIAS}

BOYD, Danah M.; ELLISON, Nicole B. Social Network Sites: Definition, History, and Scholarship (2007). In: Journal of Computer-Mediated Communication.

Disponível em: <http://jcmc.indiana.edu/vol13/issue1/boyd.ellison.html >. Acesso em: 18 fev. 2013.

BRASIL. Lei de Diretrizes e Bases da Educação Brasileira. MEC: 1996.

Disponível em: <http://portal.mec.gov.br/arquivos/pdf/ldb.pdf>. Acesso em: 12 de nov 2013.

BRASIL. Lei $\mathbf{n}^{\mathbf{0}}$ 9475, de 22 de julho de 1997: nova redação ao artigo 33 da Lei $\mathbf{n}^{\mathbf{o}}$ 9394/96. In: Diário Oficial da União, de 23 de julho de 1997, seção I. Disponível em: 
<http://www.eduline.com.br/eduline/legislacao/Lei9475.htm>. Acesso em: 12 de nov de 2012.

BRASIL. Parâmetros Curriculares Nacionais - Ensino Médio. Brasília: MEC, 200o. Disponível em: <http://portal.mec.gov.br/seb/arquivos/pdf/14_24.pdf>. Acesso em: 15 de abr 2013.

CASTELlS, M. A era da informação: economia, sociedade e cultura. São Paulo: Paz e Terra, 1999.

CONSELHO NACIONAL DE EDUCAÇÃO. Resolução CNE/CBE n. o7/10. Distrito Federal: CNE, 2010.

DELORS, J [et al.]. (1998) Educação - um tesouro a descobrir: relatório para a UNESCO da Comissão Internacional sobre Educação para o século XXI. Brasília, DF.: MEC: UNESCO.

FORUM NACIONAL PERMANENTE DO ENSINO RELIGIOSO. Caderno Temático o1. Curitiba: FONAPER, 2001.

FORUM NACIONAL PERMANENTE DO ENSINO RELIGIOSO. Parâmetros Curriculares Nacionais do Ensino Religioso. 8 ed. São Paulo: Editora AveMaria, 2006.

JUNQUEIRA, Sérgio Rogério Azevedo. Mafagafos e Mafagafinhos: Identificar, propor e ousar um Ensino Religioso e uma proposta escolar. Revista Diálogo Educacional - V.3 - n.6 - p. $107-132$ - maio/agosto, 2002.

KALINKE, M. A. Internet na educação: quando, como, onde e porquê. Curitiba: Chain, 2003.

Portal - Significados.com.br. Significado de Website. Disponível em: <http://www.significados.com.br/website/>. Acesso em 13 nov 2013 >.

RECUERO, Raquel. Comunidades Virtuais em Redes Sociais na Internet: Uma proposta de estudo. Ecompos, Internet, v. 4, n. Dez 2005, 2005.

TAJRA, S. F. Informática na educação: o professor na atualidade. São Paulo: Érica, 2001.

TOMAEL, Maria Inês, ALCARA, Adriana Rosecler e DI CHIARA, Ivone Guerreiro. Das redes sociais à inovação. Ciência da Informação, maio/ago. 2005, vol.34, n. 2, p. 93-104.

\section{Fontes primárias da pesquisa}

http://alinemarcaledreligiosa.spaceblog.com.br/

http://aspersc.blogspot.com.br/

http://avilareligioso.wordpress.com/

http://blog.educacaoadventista.org.br/blog/camoc_gabriel/

http://blog-tiaval.blogspot.com.br/p/atividades-de-ensino-religioso.html

http://castelinho-ensinoreligioso.blogspot.com.br/

http://cenfopensinoreligioso.wordpress.com/ 
http://cienciasdareligiaouern.blogspot.com.br/

http://conerrs.wordpress.com/ensino-religioso-plano-de-estudos/

http://disciplinadeensinoreligioso.blogspot.com.br/

http://educacaodareligiosidade.blogspot.com.br/

$\mathrm{http}: / /$ eensinoreligiosororaima.blogspot.com.br/

http://enreligioso.wordpress.com/

http://ensinoreligioso2.blogspot.com.br/

http://ensinoreligioso6.blogspot.com.br/

http://ensinoreligioso7.blogspot.com.br/

http://ensinoreligioso8.blogspot.com.br/

$\mathrm{http}: / /$ ensinoreligiosog.blogspot.com.br/

http://ensinoreligiosoemfoco.blogspot.com.br/

$\mathrm{http}: / /$ ensinoreligiosoemsaladeaula.blogspot.com.br/

http://ensinoreligiosonreapucarana.pbworks.com/w/page/10773758/FrontPage

http://ensinoreligiosopravaler.blogspot.com.br/

$\mathrm{http}: / /$ ensinoreligiosorse.zip.net/

http://ensinoreligioso-serafimjonas.blogspot.com.br/

http://ensinoreligiososlg.blogspot.com.br/

http://francinete-ensinoreligioso.blogspot.com.br/

http://jorcemar.blogspot.com.br/

http://kdvc-amigo.blogspot.com.br/

http://modeloplanejamentoere.blogspot.com.br/

http://pluralreligioso.blogspot.com.br/2013/o4/confira-blog-de-adriana-melloassim.html

http://portalensinoreligioso.blogspot.com.br/

http://profercontagem.blogspot.com.br/

http://religiosoressurib.wordpress.com/

http://transcender-ensinoreligioso.blogspot.com.br/

http://unisinos.br/blogs/gdirec/2012/o7/19/conheca-o-gdirec/

http://webdimension.com.br/transcendente/

http://www.cnbb.org.br/site/ensino-religioso

http://www.ensinoreligioso.seed.pr.gov.br/

http://www.fonaper.com.br/

http://www.gper.com.br/

http://www.grupos.com.br/blog/profeiraci8/

http://www.paulinas.org.br/dialogo/

http://www.unisinos.br/extensao/acao-social/assessorias-ao-ensino-religioso

http://wwwsilvanaensinoreligioso.blogspot.com.br/

https://twitter.com/EnsinoReligioso

https://twitter.com/grupogper

https://www.facebook.com/aperrs

https://www.facebook.com/aulade.filosofia.7?fref=ts

https://www.facebook.com/CantinhodoEnsinoReligioso

https://www.facebook.com/DialogoRevistadeEnsinoReligioso

https://www.facebook.com/emsinoreligioso.filosofa

https://www.facebook.com/ensino.religioso.1

https://www.facebook.com/ensino.religioso.5

https://www.facebook.com/ensinoreligioso.ptasp

https://www.facebook.com/ensinoreligiosoescolar

https://www.facebook.com/fonaper.ensinoreligioso?fref=ts 
https://www.facebook.com/formacao.continuadagper?fref=ts https://www.facebook.com/formigaethos.formigaethos.5?fref=ts https://www.facebook.com/groups/396095837113286/?fref=ts https://www.facebook.com/groups/416475935079995/ https://www.facebook.com/grupogper?fref=ts https://www.facebook.com/mariajose.torresholmes?fref=ts https://www.facebook.com/MetodologiaDoEnsinoReligioso https://www.facebook.com/pages/Ensino-Religioso/595471607132628 https://www.facebook.com/pages/Organiza\%C3\%A7\%C3\%A3o-Beneficente-EducacionalEclesi\%C3\%A1stica-e-de-Ensino-Religioso/399156203493410 https://www.facebook.com/pages/O-Transcendente/550293904998409?fref=ts https://www.facebook.com/RevistaDialogo?fref=ts http://jcmc.indiana.edu/vol13/issue1/boyd.ellison.html\#introduction> http://www.educacaoetecnologia.org.br/?p=5487 